\title{
Knowledge Vocabulary and Linguistic Usages in Malayalam with Special Reference to Ayurveda
}

\section{Prameela K P}

\begin{abstract}
As studies on ancient schools of alternative medicine have been revived by various postmodern and post colonial thinkers, Ayurveda, the traditional art of healing that flourished in India during the vedic era (and had continued to be a medical practice since then) deserves special attention. The terminologies of the discipline were initially in Sanskrit but with the expansion of the system of medicine its vocabulary or in fact the entire discourse travelled to other modern languages as well. This paper takes a close look at the language of Ayurveda in Malyalam.
\end{abstract}

Key Words: Ayurveda, knowledge vocabulary, Malayalam, terminologies, interpretation

Malayalam is well known for its receiving capacity and acceptability and in terms with vocabulary, new ideas and foreign linguistic styles from all languages. In that view, it is very flexible and acquiring. There are equal, adapted and transformed popular words and terms used in the language. Generally, they are in two categories: First category is of those terms, which are scientific and the second is those, which are freely used in popular scientific books. Specifically speaking, first stream of vocabulary is for expert use, where as the second one is used for the lay readers. Distinctive styles of the texts also change according to the context and subject.

For knowledge texts, the vocabulary has a crucial role to play, it should be either fixed or a invariant in nature, easily correlated with the context in which it is used. It is assumed that the text shall constitute absolute way of knowledge carrying for certain cognitive acts. The settlement of technical terminology before the statements 
made is essential in this context. True understanding and valid knowledge carrying words and expressions serve a lot. There is no scope for 'interpretation' as in the case of literary translation.

Normally, three fold tasks are adopted in the creation of words and stipulation of meanings in this category. One, determining the meaning, two, establishing the relevance and the third is articulating the rationality. These typologies can be adopted in the propagation of regional and ethnic words related to beliefs also. For stipulating a word in a certain context, interpretational typologies suggested by the scholars are said to be annotations, paraphrase, elaboration, exposition, partial creation and creative variant on the given theme, as deliberated by Kapil Kapoor (2005:49)

Transliteration is widely used in Malayalam with regard to chemicals, names, compounds, mathematical derivations and a large number of technical terms. Abbreviations are difficult in expression in vernacular languages. But it is also tried in terms with some special contexts. Attention is needed in the translation and preservation of knowledge in Creoles and Pidgins. These shades of Malayalam are widely used in literary texts.

There was a perception that local and ethnic terms are not apt in terms of expressing scientific and knowledge. But slowly, importance of regional knowledge vocabulary has -got attention. Mixed or hybrid forms are also in use. Direct meaning, idea presentation, contextual compliance are said to be the quality of words. Detachable elements, structural matching, natural overview and minimal adjustment tendency are four important characteristics of borrowing described by Jean Aitchison (Aitchison: 142-143)

\section{Problems of translation of Ayurvedic Texts}

Our ethnic knowledge system has been highly influenced by the imported medical world. New terms were formed to cope with the changing world. Tablets and Capsules in the place of gulgulu and 
gulika has got wide acceptance. Orality and literacy have been mixed to express the terms and solutions. Krishipadhom, Ayurveda based health programmes aired through AIR and DD has maintained in popular language, with special attention to the chemical and botanical names used in the contexts. Faithful translation, free verse and recreation are the methods practically used for tackling the practical usages for fulfilling the purpose.

It is not so easy to translate the local language knowledge used by the people of the land into English, because it has only oral and ethnic tradition. There is a challenge in reviving the oral or ethnic knowledge. Many areas of modern disciplines assemble in this. Malayalam language is well known for paraphrasing or elaborating, while placing the knowledge-text vocabulary. (Madhavankutty: Vivarthanam: 126). But we can find the same trend in English while placing the Sutras and Manthras (hymns) and their glossary into English. For Example vata, pitta and kapha are expressed as biological air humor, bilological fire humor and biological water humor respectively. A number of examples can be charted out in the translation of The Legacy of Caraka (Valiathan: 2003) like texts. Use of same words owing to a pan Indian identity in the presentation of translated text is also well accepted by the Malayalam translator of Ashtangahridyam (Menon Kuttikrishna V M: 10). Multilingual perspective has its own pressures and paradoxes while using stipulated languages for knowledge text transfer. This is also due to the long and conventional type of oral tradition in which Ayurveda like subjects survived in centuries. G C Spivak has well identified this phenomenon that "The verbal text is jealous of its linguistic signature but impatient of national identity. Translation flourishes by virtue of that paradox". (Spivak: 2000/21). The history of Indian indigenous oral and written texts related to Ayurveda has been translated as an initial act of colonization, part of the process of domination of achieving control on the language and the people, identified and narrated by the later theoreticians also. (Young: 140). We can very easily find out that traditional indigenous knowledge texts has put forward its own peculiar sense of resistance, a positive one, on the intruder's version. Functional approach has extended to 
elaborate, sometimes distort the indigenous. Influence of modern, western oriented medicine on Ayurveda is not addressed in this way. Corporate forces have helped a lot to mix both in order to deceive people in the name of Health and Tourism. It is tragic to see that folk, traditional forms of medical system - Materia Medica- followed by generations of this soil has been slowly isolated and eradicated by this. It is said that kalari vaidyam, nadan chikitsa, visha chikitsa, ammumma vaidyam, marma chikitsa, ethnomedicines and their symbolic usages and applications are in-the-path-of eradication. Again their ecological associative, place and time peculiarities of disease etc are excluded in the application of new stipulated scientific medicine. Extinction of herbs and medicinal plants is well known for all. Compounds, fluids and other forms extracted has also stopped. Guru-sishya system practiced through generations has also stopped by the modern education. Stipulating botanical name for each species of plant and standardization of the term has got approval. Different names and meanings have been marginalized by this. Anthropological studies proved that meanings in any framework of social life is not confined to a single area, but cross cut many institutional structures, which make a social system. New generation physicians cannot identify them as they have been taught the newly set lessons of patent and international knowledge system. Modern medicines and their applications have faced stiff resistance from the tribal and the rural forms of applications. It is well known that relationship that binds knowledge interpretation and language has shaped the traditional intellectual system in which all branches of knowledge share some basic concepts and concerns. But this basic idea has been thrashed by the colonial system of interpretation. As put forward by Linda Tuhiwai Smith "Imperialism and colonialism brought complete disorder to colonized peoples, disconnecting them form their histories, their landscapes, their languages, their social relation and their own ways of thinking, feeling and interacting with the world. It was a process of systematic fragmentation which can still be seen in the disciplinary carve up of the indigenous world: bones, mummies and skulls to the museums, art world to private collectors, language to linguistics, customs to anthropologists, beliefs and behaviors to psychologists." (Smith: 28) 
Again, multi cultural varieties of applications has either hybridized or appropriated in the long process of standardization through English language. There are different notations used for the same thing in different types of medical systems practiced in South Asia. For example Thamara (lotus) in Ayurveda is Padmagarbha in Tibetan, Thamara in sidhaviadya and Neelofer in Unani. Likewise regional shades of different meanings for each plant or their solution are very difficult for even an expert, there is no question arises to except a translator in this work. (It is documented that there are 52 meanings used in Sanskrit text for chittamruthu). Here we have to use translation tools like, terminology, database and translation memories together to maintain the polyphonic nature of knowledge appropriation. We need to look conceptual, cognitive and communicative centrality of a text in the Indian consciousness that attests its innumerable reflections, vary according to the text chosen for translation. Inter disciplinary approach with full cooperation with learned tradition may help the modulations and adaptations. Annotation, paraphrasing, elaboration, exposition, formation and variation are different linguistic techniques discussed for the interpretation of early knowledge texts.

Distinctive and stipulated style of usage with total technical quality is essential in the formation of technical terminology. Double meaning can be disastrous. Herbs and their compounds are different in application. Examining the discourse - the lexical, the grammatical, the prepositional, the pragmatic and the discourse oriented - is important. Making, rearranging, presenting in TL, Testing according to the TL are the course of work prescribed for this. Venuti (1998:15) suggested reviewing the deliberate attempts of Domestication and Foreignization are the strategies used in all forms of texts translations. Horizontal translation is the only recommended way for these. But indigenous distinction creates disparity.

No meaning is formally equal in expression. Therefore finding functional equals is the way recommended by so many scholars in terms with knowledge text translation. Looking at the 
membership of a word inside the spectrum of its subject application will be served. Essentialism and constructivism must be incorporated in selection procedure. Inter-disciplinary approaches in selecting the words must be promoted, upheld. Divide between theory and practice must be reduced. If one language appears to have massively affected another, a closer look by the experts must be undertaken. Language alters as the needs of its users alter. So functional approach is used and recommended for the larger use. In the context of Ayurvedic text translations, the process will be the transformation of nature into data. G C Spivak (1999:164) has clearly asserted to include critical habitat in translation of rural information. According to her "The rural, is not trees and fields anymore. It is on the way to data." Thus latter scholars emphasized the paradigm to look at the wider habitat before the intellectual interventions inside a text. The tactics forwarded by Apter(2006:193) is genuine that "In addition to being expression grafted from the lexicon of environmentalists who use it to the minimal conditions necessary to sustain the life of endangered species, 1 am defining "critical habitat" as a translational medium that links territorial habitat and intellectual habitus, physical place and ideological force-field, economy and ecology".

There is no doubt that now a days, translation is the centrestage activity, crux of all linguistic and cultural activities. Vocabulary making is the process which helps the transfer. But local terms, folk usages and indigenous knowledge-vocabulary cannot be match with the so-called standard words formed by the scholars. Contextual use of the word is important in meaningful communication. Sanskrit and English hybridized terms is not recommended. Using conventional, rural and indigenous words is an attractive practice for the day. Vinay and Darbelnet's (Sager \& Hamel 2000:84-93) model of strategies and procedures like borrowing, calque, literal, transposition, modulation, equal and adaptation may be helpful for maintaining a rapport in the process of translation of knowledge texts, since they have always been incorporated and placed in the cognitive categories 


\section{REFERENCES}

Aitchison Jean. 2001 Language Change Progress or Decay, UK: Cambridge University Press

Apter Emily. 2006 The Translation Zone A New

Comparative Literature, Princeton and Oxford: Priceton University Press

Kapoor Kapil. 2005 Text and Interpretation The Indian Tradition, New Delhi: D K Print world (P) limited

Kutty Madhavan K. Vaidhyashasihram in Oru Sangham Lekhakar (Ed) 1999 Vivarthanam, Trivandrum:

State Institute of Languages

Menon Kuttikrishna V M. Tr. 1976 Ashtangahridayam, Kottayam:National Bookstall

Sager J C\& M J Hamel. (Ed) 1995 Comparative Stylistics of French and English: A Methodlogy for Translation, Amsterdam and Philadelphia PA: John Benjamins.

Smith Linda Tuhiwai. 1999 Decolonizing Methodologies Research and Indigenous peoples, London: Zed Books Limited

Spivak G C. Translation as culture, Parallax 6(1) Jan-March 2000

Valiathan M S. 2003 The Legacy of Caraka, Hyderabad: Orient Longman private Limited

Venuti Lawrence. 1998 The Scandals of Translation: Towards an Ethics of Difference, London: Routledge

Young J C Robert. 2003 Post Colonialism: A very short introdtion, London: Oxford

(Paper presented in the Seminar, "Growth of Malayalam Language and the Role of Knowledge Text Translation" on January 29, 2011.) 